\title{
DOA DALAM TRADISI ISLAM JAWA
}

\author{
A6dul Wahab Rosyidi \\ Fakultas Humaniora dan Budaya UIN Maulana Malik Ibrahim Malang \\ Jalan Gajayana 50 Malang Telp. 0341 410069/08125240168 \\ email:aw_rosyidi@yahoo.co.id
}

Abstract

Doa etymologically means request something to God in certain ways. while some ulama define doa is a self statement presence to Allah the Almighty about our weakness, shortages, inabilities, and disgraces, then we ask Allah the Almighty in order the weaknesses, shortages, inabilities, and humiliations are removed and replaced with the strengths, capabilities and a high degree both in human sight and in Allah sight. In the theory needs said, that basically human beings need to feel safe (safety need), and the safety need leads to the two forms, namely: safety needs of life and safety needs of the property. Safety needs emerged as the most important requirement if psychology needs have been fullfilled. this behavior as reflected in the lives of Javanese who always do doa in the form of slametan ceremony. Slametan aims to achieve slamet (safety), namely a condition in which the events will move smoothly to follow a predetermined path and will not happen misfortunes to just anyone.

Doa Secara etimologi artinya memohon sesuatu kepada Allah SWT dengan caracara tertentu. Sedangkan beberapa ulama mendefinisikan doa berarti pernyataan diri ke hadirat Allah SWT tentang kelemahan, kekurangan, ketidakmampuan serta kehinaan kita, kemudian kita memohon sesuatu kepada Allah SWT agar kelemahan, kekurangan, ketidakmampuan serta kehinaan ini diangkat dan digantikan dengan kelebihan, kemampuan serta derajat yang tinggi baik di sisi manusia maupun di sisi-Nya. Dalam teori kebutuhan dikatakan; bahwa pada dasarnya manusia membutuhkan rasa aman (safety need), dan rasa aman itu mengarah pada dua bentuk yakni kebutuhan keamanan jiwa dan keamanan harta. Kebutuhan rasa aman muncul sebagai kebutuhan yang paling penting kalau kebutuhan psikologis telah terpenuhi. Hal tersebut sebagaimana tercermin 
dalam perilaku hidup orang Jawa yang selalu melakukan Doa dalam bentuk upacara slametan. Slametan bertujuan untuk mencapai keadaan slamet, yaitu suatu keadaan dimana peristiwa-peristiwa akan bergerak mengikuti jalan yang telah ditetapkan dengan lancar dan tak akan terjadi kemalangan-kemalangan kepada sembarang orang.

Key words: pray, slametan, peaceful, prosperity

\section{Pendahuluan}

Dalam kehidupan beragama dan proses mengarungi kehidupan, doa merupakan komponen yang penting. Kepentingan itu terlihat manakala seseorang sedang dilanda rasa tidak nyaman. Disitulah muncul naluri keberagamaan yang sudah menjadi ritual agama dan disebut dengan berdoa. Kebutuhan tersebut meliputi perlindungan dalam hubungan antara manusia dengan Tuhan serta hubungan manusia dengan sesama atau dengan alam sekitar, kaitannya dengan "peluang" memenuhi kebutuhan dalam kehidupan. Oleh karena itu mengetahui posisi doa khususnya dalam konsep ajaran Islam dan Kejawen sangat penting. Dalam hal ini untuk menguatkan tatanan keimanan dan memperluas wawasan keagamaan dalam kerangka kajian ilmiah.

Dalam kehidupan sehari-hari kita telah saksikan berbagai kegiatan ritual (berdoa meminta keselamatan) utamanya di masyarakat Jawa yang terkadang memasuki wilayah syirik dalam pandangan Islam, akan tetapi kegiatan tersebut dilakukan oleh mayoritas kaum muslimin Jawa. Tradisi yang demikian telah mengakar dalam kehidupan masyarakat Jawa atau keluarga Jawa, bila ditelaah secara mendalam banyak terdapat nilai-nilai yang diakomodasi oleh ajaran Islam, walaupun tidak menutup kemungkinan terjadinya ketimpangan sebagian tradisi dari ajaran-ajaran Islam.

\section{Pengertian Doa}

Doa berasal dari bahasa Arab, yang terdiri dari dua akar kata, daa yadu du'aan wa da'watan, yang berarti menyeru, memanggil, mengajak memohon, minta tolong, menamakan dan mengundang/menjamu (Munawir, 1984: 406). Secara etimologis, doa berarti memohon sesuatu kepada Allah SWT dengan cara-cara tertentu. Sebagian ulama mengatakan bahwa, doa berarti pernyataan diri ke hadirat Allah SWT tentang kelemahan, kekurangan, ketidakmampuan serta kehinaan kita, lalu kita memohon sesuatu kepada Allah SWT agar kelemahan, kekurangan, ketidakmampuan serta kehinaan ini diangkat dan digantikan dengan kelebihan, kemampuan serta derajat yang 
tinggi baik di sisi manusia maupun di sisi Allah SWT itu sendiri. Sekalipun demikian, pemahaman doa dari perspektif bahasa dan etimologi akan lebih lengkap apabila disertai penjelasan doa dalam konsep al Quran.

\section{Konsep Doa dalam al Quran}

Secara bahasa sebagaimana tersebut di atas kata doa berasal dari kata daaa yadu duaaan wadawatan yang mempuyai banyak arti, dan sebagaimana pula terkonsep dalam ayat-ayat al Quran al Karim. Doa dalam hal ini memiliki beberapa pengertian antara lain:

1) Permintaan (Assual) sebagaimana firman Allah SWT dalam QS al Mukmin: 60:

Dan Tuhanmu berfirman: Mintalah kepadaKu, niscaya akan Kuperkenankan bagimu. Sesungguhnya orang-orang yang menyombongkan diri dari menyembahKu (berdoa kepadaKu) akan masuk neraka jahannam dalam keadaan hina dina.

Ungkapan Astajib dalam rangkaian ayat tersebut merupakan tanggapan langsung dari Allah SWT akan permintaan kita dengan syarat bahwa dalam memanjatkan doa kepada-Nya, kita harus melakukan dengan niat yang ikhlas dan kemauan yang sungguhsungguh.

2) Minta Tolong (Istighatsah) sebagaimana firman Allah dalam QS al Baqoroh: 23 yang artinya: Dan jika kamu (tetap) dalam keraguan tentang al Quran yang kami wahyukan kepada hamba kami (Muhammad), buatlah satu surat (saja) yang semisal al Quran itu dan ajaklah penolong-penolongmu selain Allah, jika kamu orang-orang yang benar.

Tantangan Allah ini secara langsung disampaikan kepada orangorang musyrik untuk membuktikan kebenaran yang mereka agungagungkan bahwa mereka lebih suka meminta pertolongan kepada orang atau setan, yang dipercayai dapat mengabulkan doa-doa mereka.

3) Pujian atau Sanjungan (as Tsana) sebagaimana firman Allah dalam QS al Isra: 110) yang artinya:

Katakanlah: "Serulah Allah atau Serulah ar Rahman. dengan nama yang mana saja kamu seru, dia mempunyai al asmaaul husna (namanama yang terbaik) dan janganlah kamu mengeraskan suaramu dalam shalatmu dan janganlah pula merendahkannya dan carilah 
jalan tengah di antara kedua itu”.

Maksud seruan disini adalah memujilah Allah sepanjang pagi dan petang dengan nama-nama Allah yang terbaik yang melekat pada dzat Allah (asmaul khusna)

4) Perkataan atau ucapan (al Qawl) sebagaimana firman Allah dalam QS Yunus: 10 yang artinya: Doa mereka di dalamnya ialah: "subhanakallahumma, dan salam penghormatan mereka ialah: "salam"(sejahtera dari segala bencana). dan penutup doa mereka ialah: "alhamdulilaahi rabbil aalamin.

Dalam konteks ayat tersebut, do'a dipergunakan dengan arti perkataan atau ucapan. Yaitu, sebuah ucapan atau perkataan tertentu yang disampaikan oleh seseorang dalam menyebut kebesaran Allah. Ucapan demikian sering muncul dalam kalimat doa.

5) Sembahan (ibadah), sebagaimana peringatan Allah kepada orangorang musyrik, kita diharapkan senantiasa tidak menyembah dan meminta pertolongan apapun kecuali hanya kepadaNya. Allah SWT berfirman dalam QS Yunus: 106 yang artinya: "Dan janganlah kamu menyembah apa-apa yang tidak memberi manfaat dan tidak (pula) memberi mudharat kepadamu selain Allah; sebab jika kamu berbuat (yang demikian), itu, maka sesungguhnya kamu kalau begitu termasuk orang-orang yang zalim".

6) Seruan atau ajakan (al Dawah)

"Serulah (manusia) kepada jalan Tuhan-mu dengan hikmah dan pelajaran yang baik dan bantahlah mereka dengan cara yang baik. Sesungguhnya Tuhanmu dialah yang lebih mengetahui tentang siapa yang tersesat dari jalan-Nya dan dialah yang lebih mengetahui orangorang yang mendapat petunjuk". QS an Nakh:125

Yang perlu diperhatikan dalam konsep doa disini adalah bahwa berdoa tidak sama dengan meminta atau memohon kepada seseorang, karena doa mengandung pengertian yang lebih khusus yaitu; hubungan vertikal seorang hamba dengan kholiqnya. Didalam doa sesungguhnya terdapat tiga unsur yang sangat penting yaitu:

1). Pernyataan seorang hamba tentang eksistensi Allah SWT. Dengan kata lain, seorang hamba yang merasa yakin sepenuhnya bahwa Allah SWT memang ada, Maha Kuasa, Maha Pemurah dan Penyayang selaku Dzat Paling Agung. Dialah satu-satunya Dzat yang patut dimintai pertolongan, tiada yang lain yang dapat memberikan 
manfaat dan mendatangkan mudharat selain diri-Nya. Maka hendaknya seorang hamba hanya senantiasa berdoa, memohon sesuatu kepada Allah SWT saja dengan penuh keyakinan bahwa di tangan Allah SWT terletak segala kekuasaan mutlak untuk mengabulkan segala permohonan.

2). Pernyataan seorang hamba tentang ketidakberdayaannya. Setelah berusaha sungguh-sungguh, pada akhirnya seorang hamba akan pasrah kepada Allah SWT karena dia yakin bahwa segala usaha yang telah dilakukan hanyalah sebatas ikhtiar belaka. Bukan dia sendiri yang sanggup menentukan hasil akhirnya, tapi masih ada kekuatan lainnya yaitu Allah SWT. Pengakuannya bahwa dia adalah makhluk yang lemah, makhluk yang tidak cukup pengetahuan dan pengalaman, serta tidak berkuasa dalam menentukan hasil merupakan unsur penting dalam setiap doa.

3). Wujud nyata introspeksi diri. Selaku hamba Allah SWT yang sangat lemah, kita harus senantiasa menyadari status kita di hadapanNya. Namun, dibalik kelemahan itu, kita juga harus yakin adanya eksistensi Allah SWT, Dzat Maha Kuasa yang sanggup mengabulkan doa-doa kita sepanjang kita dekat dan taat dalam menjahui segala larangan dan mentaati segala perintahNya. Sebaliknya, kita juga tidak boleh khilaf bahwa Allah SWT pasti tidak akan mengabulkan permintaan kita selama kita masih melanggar segala larangan dan menjahui segala perintah-Nya (Sudarmaji, 2005: 66-68).

Demikian konsep doa dalam al Quran sebagaimana tersebut, di atas dimana itu merupakan permintaan, permohonan, pujian, percakapan, ibadah, seruan atau ajakan, yang hanya tertuju pada Allah SWT semata, sang pencipta alam semesta. Karena didasari atas keimanan dan rasa ketidakberdayaan dalam diri seorang muslim.

Disamping konsep tersebut, kita juga bisa melihat bagaimana konsep doa dalam masyarakat Arab, namun di sini perlu dibedakan antara Arab sebelum datangnya Islam dan sesudahnya. Masyarakat Arab sebelum datangnya Islam, adalah masyarakat yang menganut kepercayaan paganisme, mereka berdoa ketika mendapatkan dirinya dalam kondisi yang menyulitkan kepada Tuhan-tuhan sembahannya yang dianggapnya memberikan sesuatu kekuatan dan kelebihan. Dalam berdoa mereka selalu mengucapkan dalam bentuk kalimat mantra lewat syair-syair yang disusun dengan gaya bahasa yang tinggi. Sebagaimana 
pernyataan Allah SWT dalam QS. al Baqorah: 23, yang menyatakan: “..... dan ajaklah penolong-penolongmu selain Allah, jika kamu orang-orang yang benar". Tantangan Allah SWT ini secara langsung disampaikan kepada orang-orang musyrik untuk membuktikan kebenaran yang mereka agung-agungkan bahwa mereka lebih suka memohon pertolongan kepada orang atau setan selain Allah SWT, yang dipercayai dapat mengabulkan doa-doa mereka.

\section{Konsep Doa dalam Masyarakat Jawa}

Konsep doa dalam masyarakat Jawa tidak jauh berbeda juga dengan konsep doa dalam masyarakat Arab sebelum datangnya Islam, karena proses keyakinan yang terjadi dalam masyarakat Jawa hampir sama dengan apa yang terjadi dalam masyarakat bangsa Arab, hanya perbedaannya terletak pada letak geografis yang dekat bahkan sebagai tempat turunya agama-agama samawi.

Masyarakat Jawa sebelum datangnya Islam mereka menganut kepercayaan animisme dan dinamisme, kepercayaan pada benda-benda yang dianggap bertuah dan kepercayaan pada roh yang memiliki kekuatan yang luar biasa. Mereka berdoa memohon segala sesuatu dalam hidupnya dengan cara membawa sesajen dan mengucapkan mantra-mantra yang dapat mendatangkan roh yang dipercayai itu, lantas mereka mengucapkan apa yang menjadi permintaannya. Doa biasanya dilakukan di tempat-tempat tertentu yang dianggap sakral dan angker serta dirangkai dalam upacara slametan .

Dalam tradisi masyarakat Jawa berdoa sering kali dilakukan dalam rangkaian upacara slametan, pada setiap kesempatan kalau terjadi krisis kehidupan dan pada peristiwa-peristiwa kemasyarakatan yang berulang untuk menjamin kesinambungan secara tenang. Dalam teorinya semua peserta mempunyai status ritual yang sama, setiap orang memberi sumbangan yang sama kepada kekuatan spritual dari peristiwa itu. Oleh karena itu slametan menunjukkan adanya masyarakat yang rukun, yang hal itu merupakan prasyarat untuk memohon secara berhasil berkah dari tuhan, roh halus, dan nenek moyang (Geertz, 1983: 11).

Slametan merupakan ritual pokok untuk melanjutkan, mempertahankan atau memperbaiki tatanan; dan itu merupakan sajian makan bersama yang bersifat sosiol-religius dimana tetangga berikut sanak keluarga dan teman ikur serta didalamnya. Slametan bertujuan untuk mencapai keadaan slamet, yaitu suatu keadaan dimana peristiwa-peristiwa akan bergerak mengikuti jalan yang telah ditetapkan dengan lancar dan tak akan terjadi kemalangan-kemalangan kepada sembarang orang (Kuntjaraningrat, 2002: 95). 
Hal senada juga diungkap oleh (Mulder, 2001: 136) slametan memperlihatkan hasrat mencari keselamatan dalam dunia yang kacau. Kegiatan itu tidak ditujukan bagi sebuah kehidupan yang lebih baik, kini maupun dimasa mendatang, tetapi lebih ditunjukkan untuk memelihara tatanan dan mencegah datangnya bala. Hal tersebut juga terlihat, bagaimanapun bahwa manusia memegang peran aktif dalam memelihara tatanan ini dan mampu mempengaruhi arahnya. Hubungan sosial yang tertata baik menjadi sebuah sarana menuju dan sebuah kondisi untuk meningkatkan keadaan slamet. Akan tetapi karena suatu hal mungkin saja terjadi, dan hampir-hampir tak bisa dihindari lagi, kalangan abangan yang menyadari hal ini, mempersonifikasikan kemungkinan kemalangan ini dipandang dari segi kepercayaan terhadap roh-roh halus dan mencoba tawarmenawar dengan mereka melalui upacara slametan (Geertz, 1983: 18).

Wewet misalnya, merupakan slametan bagi masyarakat Jawa untuk hasil panen, baik itu sawah maupun ladang. Slametan ini merupakan bentuk syukur masyarakat kepada Tuhan yang Maha Esa atas tanaman pertanian yang mereka tanan akan dan telah membuahkan hasil. Mayoritas masyarakat Jawa mengenal tradisi slametan untuk panen hasil pertanian. Akan tetapi inti dari tradisi yang dijalankan itu sama, yakni ungkapan rasa syukur akan keberhasilan hasil pertanian dan permintaan (doa) keselamatan.

Selain acara slametan akan mulai memanen hasil tanam, juga ada acara slametan untuk memulai bercocok tanam, misalnya bibit yang akan ditanam harus dibacakan doa "kaki nini bumi nini, kaki rumeso nini rumeso, kulo bade nanem pantun" (doa didapat dari seorang dukun bayi masyarakat Dusun Genting Merjosari mbok Watiah). Untuk doa memanen hasil; "Sri koncong/ Sri sedono (Sri koncong untuk padi, sri sedono untuk jagung), panjenengan bade kulo polong.

Dari doa yang mereka baca tersebut di atas, terlihat bahwa mereka sangat menghormati tanaman pertanian, karena dari situlah merupakan sumber utama untuk kelangsungan hidup mereka. Jika ritual tersebut tidak dilakukan, maka hasil tanaman tidak akan bagus, lebih lanjut mbok Wat mengatakan "yen slametan niku mboten dilaksanakne, bisa-biso uripe tiang ingkang gadah tegal, urepe boten ate tentrem" (jika slametan ini tidak dilaksanakan, maka orang yang punya ladang hidupnya tidak akan tentram). Mbok Wat berpendapat bahwa: Dusun Genting bisa tentram dan jauh dari musibah karena tradisi yang ada di Desa tersebut masih patuh dilaksanakan dan dipercayai.

Adapun nilai manfaat yang terkandung dalam pelaksanaan slametan wewet ini antara lain; 

a) Ungkapan syukur pada Tuhan Maha Esa
b) Tanaman pertanian mereka terjaga dari hama maupun makhluk- makhluk penggangu lainnya
c) Hasil pertanian diharapkan melimpah ruah
d) Orang yang slametan beserta keluarganya dapat hidup tentram lohjinawi dan panjang umur.

Adapun prosesi tradisi wewet sebagai berikut; sebelum melaksanakan tradisi slametan wewet, perlu dipersiapkan perlengkapan yang diperlukan seperti bahan-bahan berikut ini;

a) Pisang satu tangkai, ditaruh dibak yang cukup besar, ditengahnya diberi beberapa tempat yang terbuat dari daun pisang dan dibentuk seperti mangkok yang kotak (taker) yang berisi antara lain; taker pertama berisi satu paket bunga yang biasa untuk ditabur di atas makam, dan bumbu kinang (buah pinang, sirih, dan kapur sirih/ injet). Taker kedua berisi bumbu dapur yakni; garam, cabe rawit satu buah, kacang tanah tiga biji, daun jeruk purut tiga lembar, kencur, jahe, trasi, micin/vitsin, mentimun dan cikalan (pecahan kelapa) yang dipanggang. Taker ketiga berisi campuran parutan kelapa dengan gula.

b) Nasi pecelan (tumpeng) yang terdiri dari; satu nampan nasi kuning yang tengahnya dibentuk seperti gunung (buceng), satu butir telur yang telah dikukus dan ditaruh diatas nasi yang telah dibentuk seperti gunung, untuk pelengkapnya disekitar nasi buceng diberi sayur trancam, mie, tahu tempe, sambal goreng dan kentang-wortel. Satu ekor ayam panggang, yang lengkap tidak ada yang boleh tertinggal satupun diletakkan bersama nasi tumpeng di dalam nampan.

c) Selendang

d) Kemenyan secukupnya dan segenggam jerami untuk membuat bara api.

Setelah semua perlengkapan telah disiapkan, orang yang mempuyai hajat menggendong semua perlengkapan menjadi satu dengan selendang yang telah disediakan untuk berangkat ke ladang, dan pada malam hari akan penen diadakan slametan di rumah, dengan mengundang kaum adam untuk berdoa, baru keesokan harinya ketika berangkat ke ladang orang yang mempunyai hajat mengundang para tetangga dekat atau siapa saja yang dijumpainya sepanjang perjalanan ke ladang untuk mengikuti acara slametan wewet tersebut, setelah sampai di ladang, perlengkapan slametan ditaruh dan sang dukun atau sesepuh 
dusun membacakan doa. Adapun doa sebagaimana berikut;

"Salamolekom salam, siro alim ingson kasar, siro weruh ingson, ingson dak weroh siro, salamolekom salam. Bismillahirrohmanirrahim, niat ingson bessem sekol arum samean gondo, samean roso, wonten kirang-kirangane kulo sunngoh nedi ngapuro, salamolekom salam".

Kemudian setelah itu sang dukun atau sesepuh dusun membakar kemenyan, lalu sang dukun membawa satu takir yang berisi campuran parutan kelapa dengan gula untuk mengelilingi ladang sambil menaburkannya pada tanaman, karena diyakini hal itu akan menghilangkan hama tanaman. Sedangkan takir yang berisi bumbu, kembang dan sirih ditaruh dipinggir ladang, sedangkan yang lain dimakan orang-orang yang ikut hadir dalam slametan tersebut. sang dukun memulai memetik atau mengambil tanaman ladang dengan membaca doa; "sri koncong/sri sedono panjenengan bade kulo polong". Setelah tumpeng dimakan, para pekerja pemilik ladang mulai bekerja memanen, sedangkan yang lain pulang kerumah masing-masing.

Demikian konsep doa dalam masyarakat Jawa, mereka selalu meminta dan memohon serta mengungkapkan rasa syukur dalam bentuk doa yang dirangkai dengan upacara slametan. Slametan yang dimaksud adalah keadaan selamat dalam hidup tidak ada satupun kondisi yang membahayakan baik bagi dirinya atau orang lain.

\section{Peranan Doa dalam Masyarakat Islam Jawa.}

Semua upacara orang Jawa yang mentradisi, sebenarnya berkaitan erat pula dengan dorongan emosi keagamaan. Pada masyarakat yang diyakini mengandung nilai-nilai luhur dan mempuyai kekuatan mengikat kepada masyarakat, bila tidak dilakukan atau dilanggar akan mengakibatkan munculnya rasa ketakutan, kegelisahan, ketidak tenangan dalam hidupnya. Pada suatu yang bersifat supranatural seperti rasa takut dari gangguan roh-roh halus, takut tidak diberi keselamatan oleh Tuhan dan sebagainya. Adanya rasa takut, gelisah dan tidak tenang inilah menyebabkan mereka melakukan doa (upacara slametan).

Hal tersebut di atas bisa kita simak pengungkapan rasa ketakutan tidak tenang bila tidak melaksanakan upacara atau mengadakan slametan, ini seperti yang diungkapkan oleh salah satu warga dusun Genting Merjosari yang menyatakan dalam bahasa Jawa "Menawi mboten ngelampahi slametan puniko mboten alangan kasunyatan, nanging nemu raos mboten sekeco lan menawi tumindak wonten ing kalempahan, marahaken sakit, angel, peteng lan sak piturutipun. 
Kawontenan wau sampun tambebana saking Gusti Allah." Artinga kurang lebih sebagai berikut: jika tidak mengadakan slametan itu tidak ada halangan secara nyata tapi terasa dalam hati tidak enak dan jika terwujud dalam tindakan, menjadi sakit, menemui kesulitan, gelap, kacau dan seterusnya. Keadaan seperti itu namanya sudah menerima halangan dari Tuhan.

Slametan memainkan peran yang penting dalam tradisi-tradisi Jawa. Gerrtz mendiskripsikan slametan sebagai simbol mistik sosial bagi orang Jawa. Slametan merupakan hal yang esensi dalam upacara agama Jawa, dan merupakan bentuk upacara animis untuk mempererat solidaritas orang-orang Jawa. Ada dua aspek penting yang terdapat dalam upacara slametan yaitu spritual notion dan social integration.

Sebagaimana contoh dalam memberikan sambutan (mengujubkan) yang diwakilkan, tuan rumah biasanya selalu mengatakan;

1. Para tamu undangan sebagai saksi dari keikhlasan dan kesungguhan niatnya, dan tuan rumah berharap agar mereka semuanya memperoleh berkah dari yang ditimbulkan oleh upacara ini.

2. Agar dirinya, keluarga, dan tamu-tamunya memperoleh ketenangan jiwa dan raga, suatu ketenangan negatif yang istimewa yang oleh orang jawa disebut slamet, untuk maksud itulah ia bermohon kepada arwah-arwah di desa itu, laki-laki maupun perempuan.

Mengapa orang Jawa selalu menyelenggarakan slametan? Bila kita mengadakan slametan, tak seorangpun merasa dirinya dibedakan dari orang lain dan dengan demikian mereka tidak mau berpisah. lagi pula suatu slametan menjaga kita dari roh-roh halus, dan dengan begitu tidak akan menggangu kita. Dalam suatu slametan setiap orang diperlakukan sama, hasilnya adalah tak seorang pun merasa lebih rendah dari yang lain, dan tak seorang pun punya keinginan untuk memencilkan diri dari orang lain. Dan juga setelah kita menyelenggarakan slametan, arwah setempat tidak akan menggangu kita, tak akan membuat kita merasa sakit, sedih, atau bingung. Sasaran-sasaran itu adalah negatif dan bersifat kejiwaan, ketiadaan perasaan agresif terhadap orang lain, ketiadaan kekacauan emosional. Keadaan yang didambakan adalah selamat, yang oleh orang jawa didefinisikan sebagai "gak ono opo-opo" (tidak ada apa-apa tak ada sesuatu yang menimpa seseorang, atau dalam bahasa Geertz disebut dengan spritual notion dan social integration.

Teori kebutuhan Abraham Maslow, sebagaimana dikutip oleh (Sobur, 2010: 275) dikatakan; bahwa pada dasarnya manusia membutuhkan rasa aman 
(safety need), dan rasa aman itu mengarah pada dua bentuk yakni; kebutuhan keamanan jiwa dan keamanan harta. Kebutuhan rasa aman muncul sebagai kebutuhan yang paling penting kalau kebutuhan psikologis telah terpenuhi. Ini meliputi kebutuhan perlindungan, keamanan, hukum, kebebasan dari rasa takut, dan kecemasan. Dalam pandangan Maslow dalam (Sobur, 2010: 278), kebutuhan rasa aman sudah dirasakan individu sejak kecil ketika ia mengeksplorasi lingkungannya. Oleh karena itulah manusia selalu memohon perlindungan akan keamanan dan ketenangan dirinya dengan meminta bantuan dari kekuatan yang ada diluar dirinya yang dianggap sanggup melindungi dan memenuhi kebutuhannya, hal itu dilakukan dengan cara berdoa.

Apa yang dimaksud dengan lingkungan dalam pandangan psikologi adalah segala sesuatu yang mengelilingi individu di dalam hidupnya, baik dalam bentuk lingkungan fisik seperti orang tuanya, rumahnya, kawan-kawannya bermain, masyarakat sekitarnya maupun dalam bentuk lingkungan psikologis seperti misalnya perasaan-perasaan yang dialaminya, cita-citanya, persoalan-persoalan yang dihadapinya dan sebagainya (Patty, 1982: 58). Sejak lahir bahkan sejak di dalam kandungan, seorang individu selalu dipengaruhi oleh lingkungannya. Jika selama masa-masa dalam kandungan, ibunya mendapatkan makanan yang sehat, melakukan latihan-latihan olah raga yang tepat, mengalami ketentraman batin dan sebagainya, maka bayi yang ada dalam kandungan kemungkinan besar akan lahir sebagai seorang bayi yang sehat. Begitu seterusnya setelah lahir ke dunia ia akan selalu dipengaruhi oleh lingkungannya. Maka doa yang dipanjatkan semua akan mengarah pada kehidupan masa datang yang lebih baik dari yang sudah dijalaninya.

Masih dalam pandangan psikolog bahwa mekanisme jiwa yang menimbulkan penyakit-penyakit yang pada dasarnya bukan karena kerusakan organik pada tubuh, akan tetapi karena kondisi-kondisi jiwa, perasaan tertekan, kecewa, gelisah, dan sebagainya, yang dalam hal ini disebut psikosomatic 'jasmani sakit jiwa sakit' (Darajat, 1970: 31). Kondisi kejiwaan tersebut hampir dialami oleh setiap orang, oleh karenanya orang jawa selalu melakukan doa (slametan) agar terjauhkan, dengan mengkaitkan benda-benda, tempat, dan para arwah nenek moyangnya untuk mendapatkan kondisi yang tentram. Sedangkan Islam mengajarkan untuk mendapatkan ketenangan jiwa agar manusia selalu ingat Allah SWT, "Ketahuilah hanya dengan mengingat Allah engkau akan medapatka ketenangan jiwa”(QS ar Rodu: 28), dan doa merupakan salah satu cara untuk mengingat Allah.

Dalam pandangan ahli ilmu jiwa agama, salah satu proses yang dialami 
jiwa manusia untuk dekat dengan tuhannya adalah; masa ketidaktenangan; konflik dan pertentangan batin berkecamuk dalam hatinya, gelisah, putus asa, tegang, panik dan sebagainya, baik disebabkan oleh moralnya, kekecewaan atau kondisi apapun juga. Pada masa tegang, gelisah, dan konflik jiwa yang berat itu, biasanya orang mudah perasa, cepat tersinggung dan hampir-hampir putus asa dalam hidupnya, dan mudah terkena sugesti (Darajat, 1970: 31). Tuhan dalam konsepsi masyarakat Jawa adalah kekuatan luar biasa yang ada diluar dirinya, yang sanggup menjaga, melindungi dan memberi hajat hidupnya. Sedangkan dalam Islam adalah Allah SWT dzat yang maha segala-galanya. Sugesti dalam hal ini bisa mengarah pada positif (Allah) dan bisa juga yang negatif (tuhan, arwah leluhur dll), hal ini tergantung pada lingkungan yang mempengaruhinya.

\section{Simpulan}

Islam datang dengan ajarannya yang sempurna memenuhi semua aspek kebutuhan hidup manusia baik yang bersifat jasmani atau rohani, dan doa merupakan salah satu cara untuk memenuhi kebutuhan yang ada dalam diri manusia tersebut. Jiwa manusia tidak selamanya dalam kondisi yang stabil (muthmainnah), jiwa bisa mengalami kondisi konflik dan pertentangan, batin berkecamuk dalam hatinya, gelisah, putus asa, tegang, panik dan sebagainya. Kondisi yang seperti inilah yang tidak membuat hidup manusia menjadi tentram, dan kondisi seperti ini pula biasanya mampu membimbing seseorang untuk berdoa (slametan) agar tentram dan selamat. Doa dalam "Islam" dengan beberapa konsepnya, dan Doa dalam masyarakat Jawa " dalam bentuk upacara Slametan" pada dasarnya memiliki tujuan yang sama yaitu ingin mencari keadaan tentram, selamat, dan sejahtera. Akan tetapi muara akhir dari doa yang dipanjatkan oleh masyarakat Jawa hanya terbatas pada ketentraman kehidupan dunia, belum mencakup kehidupan akhirat. Pengakuan adanya kekuatan yang lebih (maha) pada jagad raya ini dalam tatanan sikap masyarakat Jawa belum mampu untuk mencapai kekuatan tunggal yaitu Allah SWT.

\section{Daftar Pustaka}

Al Quran al Karim. Mushaf al Madinah an Nabawiyah. Majma al Malik Fadh Lithobati al Mushaf al Syarif.

Darajat, Zakiyah. 1970. Ilmu Jiwa Agama. Jakarta: Bulan Bintang.

Departemen Agama RI. 1992. al Quran dan Terjemahan. Semarang: PT. Tanjung Mas Inti. 
Geertz, Clifford. 1983. Abangan Santri Priyayi dalam Masyarakat Jawa. Jakarta: Pustaka Jaya.

Koentjaraningrat. 2002. Pengantar Ilmu Antropologi. Jakarta: PT. Rineka Cipta.

Mulder, Niels. 2001. Mistisme Jawa Ideologi Di Indonesia. Jogyakarta: LKiS.

Munawir, A,W. 1984. Kamus al Munawir Arab-Indonesia Terlengkap. Jakarta: Pustaka Progresif.

Patty, F. MA et all. 1982. Pengantar Psikologi Umum. Surabaya: Usaha Nasional.

Sobur, Alex. 2010. Psikologi Umum dalam Lintas Sejarah. Bandung: Pustaka Setia. Cet. III.

Sudarmaji. 2005. Ensiklopedi Ringkas al Quran Jilid 2. Jakarta: Lintas Pustaka. 